2018-10

Investigating Malaysian Nurses'

perspectives of intercultural teaching in

transnational higher education learning environments

Arunasalam, N::0000-0003-2040-8321

http://hdl.handle.net/10026.1/12553

10.1016/j.nedt.2018.07.011

Nurse Education Today

Elsevier

All content in PEARL is protected by copyright law. Author manuscripts are made available in accordance with publisher policies. Please cite only the published version using the details provided on the item record or document. In the absence of an open licence (e.g. Creative Commons), permissions for further reuse of content should be sought from the publisher or author. 


\section{Investigating Malaysian Nurses' Perspectives of Intercultural Teaching In Transnational Higher Education Learning Environments}

1.Dr Nirmala Devi Arunasalam, EdD, SFHEA, PGDip, MSc, BSc, DipHE in Nursing, RN

2.Associate Professor Robert Burton, EdD, RNLD, FHEA, CMI, MBA, MEd, BSc (Hons)

1.School of Nursing and Midwifery, University of Plymouth, United Kingdom

2.School of Nursing and Midwifery, Griffiths University: Singapore

Correspondence address: Dr Arunasalam: 104, 3 Portland Villas, University of Plymouth, Drake Circus, Plymouth, PL4 8AA.

Email address: mala.arunasalam@plymouth.ac.uk

Background: In recent years, many ASEAN countries, including Malaysia have embraced Transnational Higher Education (TNHE) post-registration top-up nursing degree programmes. These are bridging programmes that allow registered nurses to upgrade their diploma qualifications to a degree level.

Purpose: To investigate the teaching and learning experiences of Malaysian nurses on Transnational Higher Education post-registration top-up degree programmes in Malaysia.

Design: Hermeneutic phenomenology and the ethnographic principle of cultural

interpretation were used to explore the views of eighteen Malaysian nurses from two UK and one Australian TNHE universities (determined by convenience and snowball sampling methods) to ensure data saturation. Semi-structured interviews were conducted in English and Bahasa Malaysia (Malaysian language) to enable nurses' voices to define, describe and evaluate their TNHE classroom experiences.

Data Analysis: Data was analysed using thematic analysis.

Findings: The nurses' experiences within the short one or two weeks TNHE intercultural teaching and learning environment identified four categories: language and teaching and learning issues; TNHE degree requirements, guidance and support; shock and coping strategies and acclimatisation. They suggest there was a conflict between the assumptions and expectations of the TNHE 'flying faculty' and nurses' about the programme of study. There were also mismatches between Western and Malaysian pedagogical preferences, guidance and support, and professional values.

Implications for Education / Practice: There is a need for TNHE 'flying faculty' to

internationalise the theoretical knowledge to reduce cultural incongruities and dissimilarities. Cultural immersion will stimulate intercultural views and knowledge to equip nurses for promotional and/or global opportunities whilst enabling the 'flying faculty' to create new learning environments. The research provides insights to inform TNHE provider institutions to improve teaching and learning to enable nurses to make the theory-practice connection.

\section{Background}

The globalisation-internationalisation nexus in Higher Education (HE) has led to the internationalisation of $\mathrm{HE}$, 
'... Internationalization is definitely past the "new flavor of the month" stage. It is firmly embedded in institutional mission statements, policies, and strategies as well as national policy frameworks. This signals that internationalization has come of age and is a legitimate area of policy, practice, and research in higher education' (Knight, 2011:14).

The fundamental focus of Western Higher Education Institutions (HEIs) is towards market expansion, global recognition and raising their international profile. This is driven by political, economic, educational, social and technological advances (O’Mahony, 2014). Leshchenko and Avshenyuk (2015) suggest that this globalisation of education has emerged as a result of differing standards and levels of educational systems becoming evident (due to globalisation), and exposure to distance and virtual education, and leading to the emergence of transnational providers.

Internationalisation via partnerships with western countries developed quickly in South East Asia. These partnerships include international activities such as student and faculty mobility programmes, research partnerships, international academic programmes, as well as international campuses, franchises and a variety of face to face or distance delivery modes (Knight, 2004). Ahmad and Buchanan (2016) suggest the term 'glocal' describes a generation of students with global ambitions yet prefer to stay in their own region for education.

Collaborative partnerships make this possible and Malaysia is one country seen to have deliberately positioned itself as an educational hub for such transnational developments (Sidhu and Christie, 2015).

Some university Nurse Education providers in the UK and Australia have developed collaborative links with Malaysian organisations to provide Transnational Higher Education (TNHE) part-time top-up nursing degree programmes delivered by 'flying-faculty'. With these 'flying faculty' models of TNHE post-registration top-up nursing degree programmes, western academics 'fly in' from their country for delivery of one to two weeks teaching. These academics 'fly back' to their country on completion of the teaching period. Such postregistration top-up nursing degree programmes are bridging programmes that allow Diploma qualified nurses the opportunity to upgrade their existing qualifications to degree level.

The Malaysian Nursing Board allows private HEIs connected with public universities and private colleges linked to private hospitals to make collaborative links with UK and Australian HEIs, to heighten the status of nurses and to develop nurses' mind-sets to enhance patient care. Qualified and registered Malaysian nurses are motivated to upgrade their diploma to a TNHE degree level (due to the status attached to the western degrees), and meet the Malaysian Nursing Board (2008) enforced Continuous Professional Education criterion for annual re-license. A previous Chief Nurse of Malaysia influential in this development, suggested that,

"Shifting demands and the technological advances in healthcare have also created challenges for the Malaysian nursing profession. Nurses must therefore conquer these challenges by becoming more knowledgeable about their profession. The continuous education of Malaysian nurses would promote greater accountability, knowledge and personal commitment in providing healthcare to individuals throughout their lifespan." (Florina Abdullah, 2009: 2). 
In order to access these courses, nurses must be registered with the Malaysian Nursing Board and hold the Diploma in Nursing or equivalent. The course structures, teaching and learning, assessment and qualifications vary between the universities delivering TNHE nursing degree programmes in Malaysia. The form, quality and standards of the study programmes appears to vary between universities and only some of these universities have the Malaysian Quality Agency (MQA) approval or accreditation. Most courses are delivered over two years, with blocks of one or two week teaching delivered in each semester by 'flying faculty'. Following these block periods, only email contact and online support is available to the students studying on these courses. Malaysian nurses who complete the TNHE degree programme attain an academic award from the institution that developed the programme. The UK Nursing and Midwifery Council (NMC) however does not permit their registration to practice in UK as a result of these awards, neither does the Australian Nursing and Midwifery Council (ANMC) allow nurses to practice in Australia. This is due to the programme content being $100 \%$ theory based and lacks clinical practice experience and assessment.

\section{Research Question:}

The purpose of this study was to investigate the experiences of the Malaysian nurses undertaking such TNHE courses. The main research question was to ascertain 'to what extent have Malaysian nurses applied theoretical knowledge taught in TNHE post registration top up nursing degree programmes in clinical settings?'. This question was underpinned by 4 objectives for exploration which were believed to contribute to answering the question. These were to consider the nurses' perspectives on personal development, professional transformation, implementation of nurse led changes and acceptance of nurse led changes. This paper focuses on issues related to the nurses' perspectives of their experiences within the TNHE intercultural teaching and learning environment.

The findings will be presented under four categories: language and teaching and learning issues; TNHE degree requirements, guidance and support; shock and coping strategies and acclimatisation.

\section{Design}

This was a qualitative study based on a hermeneutic phenomenological approach. Hermeneutic Phenomenology is informed by the work of Max van Manen (2014). It was chosen as it required participants to re-visit, reflect and describe their lived experiences and the meanings forthcoming from this. It does not attempt to create a theoretical standpoint only to provide understanding of those experiences in context whilst also recognising the researcher's role in the process (Dowling, 2007).

Although ethnography was not employed as an approach, the ethnographic principle of cultural interpretation (Geertz, 1973) was used. This enabled the researcher as an inside, to connect with the nurses' experiences to reveal rationales and meanings (emic) that will enable outsiders to understand the phenomena (etic) (Pike, 1967).

\section{Settings}

This study was undertaken in the nurses' own clinical settings in Malaysia. This was not the perfect kind of quiet environment recommended for conducting research interviews (Polit and Beck, 2010), but the participants themselves had opted to be interviewed during breaks or after their shifts for their convenience so this was the preferable option for access to them.

\section{Participants}


The participants recruited were Malaysian nurses who had completed their TNHE nursing top up degree programme of study in Malaysia. It was important to ensure they provided their views without any fear of repercussions or negative consequences. Initially, ten participants were recruited via email by convenience sampling from the only UK university that consented to participate in this study. However, when contact details were requested to arrange interviews, only 6 participants responded. There were no further responses to the emails that were sent on three separate occasions. Snowball sampling, (Merriam, 2009), occurred when interest was shown by five nurses who had studied from other TNHE universities in Malaysia when they became aware of the study. These additional nurses were accepted, and were asked to further introduce others who had studied in similar programmes.

The nurses recruited via this method had also completed their programme of study within 6 months with one Australian and one UK TNHE provider. In total, eighteen Malaysian nurses participated in the study, drawn from one Australian and two UK TNHE universities.

\section{Methods}

Qualitative methodology was chosen as it would allow the researcher to hear Malaysian nurses' voices and further probe in an attempt to encourage and understand their outlook. Interviewing, was considered ideal to gain, develop, validate and ascertain in-depth understanding as Dempsey, Dowling, Larking and Murphy (2016: 480) suggest it is an approach that yields rich and meaningful data (in this case of nurses' experiences and also my quest for insight into their experiences), whilst ensuring the participants remain safe in light of sharing sensitive information. In addition, an interview allowed the nurses to be more confident and relaxed to express their personal views about a topic which they might have been reluctant to discuss in a group.

\section{Data Collection}

Semi-structured interviews were used to allow a conversational way of using the same questions. An eight-question interview guide was developed from the review of the literature, personal insights and experiences, and employing principles related to developing interview questions put forward by Merriam (2009) for targeted data collection. The interview guide was pre-pilot and pilot tested. The interviews were conducted in both English and Bahasa Malaysia (Malaysian language) to encourage the eighteen Malaysian nurses from one Australian and two UK and TNHE universities to describe their experiences within the intercultural teaching and learning environment to ensure data saturation. These interviews were undertaken in a room in each individual nurses' workplaces either during their breaks or after work as requested by these nurses for convenience. The 60-90 minute interviews were audio recorded and on completion of the interviews, field notes were written.

The audio recording was transcribed and sent to the eighteen interviewees. However, only ten responded despite three emails. Some personal email addresses were no longer operational, as notification of failed delivery returned whilst others simply failed to respond. All confirmed the accuracy of the record and none of them asked for any additions, amendments or removing any details.

\section{Ethical Considerations}

van Manen (2014) agrees with Cohen, Manion and Morrison (2011) that the researcher has a moral and intellectual responsibility to ensure the research is sound and trustworthy. Formal written approval was requested as emphasised when attending postgraduate training in the University. Approval was given by the University's Research Ethics Committee. The British 
Education Research Association (BERA), (2011) key principles about ethics were also acknowledged. The nurses were informed that this research was being undertaken by a Malaysian researcher for her professional doctorate and that she had previously been an international student in the UK.

\section{Data Analysis}

The interviews were analysed using thematic analysis. This is an approach to recognise and organise patterns in content and meaning, including inconsistencies (Willig, 2013). It involves reading and re-reading the data or information numerous times, then coding the information, and identifying substantive and theoretical themes that relate to the aims of the research (Polit and Beck, 2010). In this study the thematic analysis is developed from Benner's (1994) hermeneutic analysis that identified three key steps of (a) isolating paradigm cases, (b) identifying repetitious themes from within and between cases and finally (c) selecting quotes to illustrate themes. It focused on capturing the descriptions and meanings of the Malaysian nurses' experiences.

\section{Results}

All eighteen participants were female, from private hospitals and their age ranged between 21 to 50 years with two thirds of the interviewees aged between 31- 40 years (12/18). All interviewees had 5 or more years' experience and held senior positions including the one member of staff under the category 'Other' (role not stated to ensure anonymity), (17/18). There were no restrictions on the number of choices participants could select for their reasons for attending the TNHE degree programme. The main reasons cited were to update themselves i.e. interest (14/18), career development (12/18) and improving practice (11/18).

The findings indicated there appeared to be a conflict between nurses' assumptions and expectations of the TNHE programme and those of the TNHE 'flying faculty'(Arunasalam, 2013, 2017). There were also mismatches between western and Malaysian expectations of pedagogical, guidance, support and professional values. Initially, nurses experienced learning and cultural shock and had to use coping strategies to acclimatise to the intercultural teaching environment. The Malaysian nurses' pre and post registration nursing journey will be illuminated as it will give significance to the reality of their TNHE experiences. Their three year pre-registration nurse training appeared to be underpinned by the principles of a) teachers and books being authoritative knowledge sources, b) didactic teaching, c) information in books as reliable, d) bilingualism is used even if English is the approved language of instruction, e) rote or repetitive learning by memorisation for assessments in the classroom and clinical settings, f) all material required for assessments is provided, $g$ ) effortful and respectful learning were used and $\mathrm{h}$ ) assessment methods of written exams, closed-book examination, multiple choice questions, group presentations, short answer questions and Objective Structured Clinical Examinations. It appears that these did not require students to demonstrate decision making or critical thinking about the taught knowledge and procedures or skills.

In contrast, their post-basic journey centred on practice in specialised areas. Taught knowledge was in-depth to enable justification of care provision as they observed, practiced and gained competency with essential practices and skills in specialised settings. Senior nurses supported them to use deep-level thinking for integrating relevant theory to nursing practices and skills. It appears that reasoning skills were developed during their post-basic education to enable them to rationalise the management of patient care in specialised settings. 
This confirms what Kirby, Lanyon, Cronin and Sinclair (2003) identify as the salient features of deep learning styles and Gow and Kember's (1990) belief that a deep method to learning can be attained by using memorisation as a tool to improve insight.

The nurses' experiences within the TNHE intercultural teaching and learning environment and programmes, and their perspectives of it, are presented next.

\section{Language and teaching and learning issues}

The participants were initially not deterred by the anticipated differences between the eastern and western educational traditions. Instead, all indicated they were mainly positive despite mixed feelings of anxiety, fear and lack of confidence in their English Language skills and western academic practices. The participants outlined that even though they were familiar with English, they had difficulty coping with English as the medium of instruction during the classroom teaching. Interviewee 016 stated:

"I found it difficult to the language, I trying to figure one word, she has finished sentence. She said 'one die' [accent], I thought Oh dear! Who has died? Then I realise she actually meant 'one day'!".

In using the emic view, it is acknowledged that English is not their first language but a second or third language for some. In addition, the spoken English freely incorporates a mix of words or code-switching from the languages of diverse ethnic groups' and mother tongues.

"At Malaysia we not speaking English only, we mix everything, all mixed language" (Int:009). The etic perspective identifies there are variations in the pronunciations, accent and expression of the 'flying faculty' that made their presentation appear like a new language.

The nurses demonstrated silent classroom behaviour and the western academics questioned them. "You all very quiet, never ask anything. ... we understand or don't understand we keep quiet only" (Int: 006). A combination of reasons contributed to their behaviour: a) deference to authority (Abdullah \& Koh, 2009): "We cannot be open, we have our national style, hierarchy, very, very obvious!" (Int: 013); b) culture of listening to learn or save face of teacher (Hofstede \& Hofstede, 2005): “We give respect, we don't criticise or argue or give opinions" (Int: 010); c) potential for repercussions: "We have to accept, if we argue, they will say 'You are a bad student'. Then they will aim you and cut your marks" (Int: 006); d) miscommunication: "... when we ask question they explaining but we cannot catch what they are telling. Lastly, we give up" (Int: 002); e) lack of comprehension: "If we don't understand anything we don't know what to ask, right" (Int: 017); f) student saving face: "If we ask then lecturer and others will think 'she is stupid lah to ask this question!' You don't want everyone to think you stupid so you keep quiet" (Int: 006) and g) feelings of inequality with western academics: Interviewee 004 expressed "We have English person coming to teach, we feel inferiority complex."

The literature identifies differences between Malaysian and western learners in the classroom and typifies Malaysian learners as passive versus active (Abdullah, 2010; Biggs, 2014). My Malaysian emic view clarifies that students apply respectful listening and attention when the teacher speaks. There is also an accepted assumption and a sense of security among Malaysians that not being active in the classroom does not mean lack of academic ability. Likewise, participating does not indicate academic prowess. Nurses were behaving exactly as 
they would in a Malaysian classroom. Their polite, silent behaviour (Amir, 2009; Gill, 2009) suggests that the interviewees' reluctance to participate could be due to classroom etiquette as desired and defined by their home cultures rather than their approach to learning or abilities. My etic academic view is that recognition of these cultural rules by TNHE academics is vital as these hidden narratives influence the nurses' experiences in the TNHE teaching and learning environment.

\section{Theoretical knowledge and assessment}

The participants expressed that teaching content within the modules was very UK or Australia centric rather than having an international focus, as interviewee $\mathbf{0 0 7}$ commented:

"I thought, why they don't give Malaysian examples, it's good we can know their ways but all from their practice. But here, we didn't see that, we don't know."

In using my etic academic view I point out the importance to relate the TNHE theoretical knowledge by providing both western (UK or Australia) and eastern (Malaysia) examples to demonstrate the similarity and differences that will enable the widening of knowledge. My emic perspective, identifies that even if Malaysian nurses have knowledge of certain aspects they will not be able to relate it as the meaning is different and also because they are not practicing it.

Fourteen of the nurses found western critical analysis skills, to criticise others' work, to discern the value of evidence found, be convinced or remain unconvinced by the evidence and to reason logically were difficult concepts to understand and master within the short teaching period. In Malaysia, the notion of critical thinking and analysis is absent from the language and cultural frames of Malaysian society. As previously mentioned, teachers and books are considered authoritative sources in imparting knowledge (Hassan, 2010; Hassan \& Jamaluddin, 2010). In addition, information in books is accepted as reliable and undisputable as they are assumed to have been tested in practice. The student's purpose is merely to explicate, refine and support taught knowledge (c.f. Li, 2016). Questioning to make sense or justify knowledge was done mentally which is evidenced by interviewee 006's statement:

"She spoke about Indian patients in UK, but our nation, we used to Malays wear Malay clothes, Chinese, Cheong Sam and Indians, sari, they wear their traditional clothes. The lecturer said, 'Oh! No, let them wear their own traditional clothes'. I thought 'Why the big fuss about their clothing'? In Malaysia we have already done it."

On the TNHE programmes, the assessment was mainly assignments. The assessment criteria were given on the first day of the teaching period which led to anxiety, uncertainty and stress as they were not used to writing assignments such as those expected:

"You know our English standard here, speaking and writing how we will be writing our essays. 500 words also we will be struggling to write in English. In diploma we answering a,b,c,d - that's what we learn; suddenly to do essay style 2500, 3000, 5000 words is quite hard. You know to make up a word, to make up a sentence, to make it longer, we find is very difficult" (Int: 018).

My emic UK academic outlook recognised that the Malaysian nurses' teaching and learning experiences should have been identified prior to delivery of teaching to enable academic and 
critical writing support to be provided. Also, what TNHE academics considered as appropriate language, methods and evidence to support critical thinking and analysis skills were western in nature and different to the reasoning skills that are fundamental to management of care provision. Unfortunately, Jin and Cortazzi's 2013a, b) emphasis of the importance of promoting culturally open attitudes and communication between educators and international students seemed to be ignored. Also, Leask \& Carroll's (2011) belief that their learning experiences need to be supported by an international awareness and competence curriculum was not evident.

\section{Guidance and support}

The participants found the assessment criteria was difficult to decipher. Further, for fourteen of the nurses, this was their first time to write an assignment as the education and nurse education system in Malaysia does not require them to do so. They experienced feelings of fear, insecurity and inadequacy by the need to search for relevant information and literature and use enquiry skills to undertake a critical discussion of their thought processes. This could be because their former styles of learning e.g. memorisation to pass exams had been replaced by a diversity of teaching and learning styles (Ibrahim, Nik Yusoff \& Kamarudin, 2016). In addition, the lack of face-to-face guidance and support for their assessments led to challenges in completing their assessments. The TNHE 'flying faculty' lack of intercultural awareness also contributed to difficulties in communication, interpretation and understanding in the classroom, on-line forums and email exchanges.

On hindsight, my Malaysian experience outlines that the nurses were expecting TNHE academics to give them all the relevant subject information to complete their assessment. For six participants from one UK university, their lack of understanding of the required criteria, assessments and the poor face to face and on-line support, only became evident after submission of their first assignment. When the lecturer realised that none of the students had met the criteria, she arranged to meet with the nurses for three extra days in Malaysia. They had shocked reactions when informed of their failure to meet western academic standards. These standards were the demonstration of a certain level for their English language, inadequacy of their study skills, critical evaluative thinking in their assignment and certain academic writing skills that had not been taught during the teaching period. It was to ensure they met the assessment criteria for their re-submission. This was expressed by all nurses, as verbalised by interviewee $\mathbf{0 1 0}$ :

"Very hard, most of us doesn't know what we doing, we had to write 5000 words, it's not medical words but this is totally different. First module we all didn't meet criteria, so all had to do it again. Only then knew our English not good. She said be more critical, not descriptive - how? Reference list, key point in each paragraph and some other things and plagiarism taught on another extra three days. This was not told in the 2 week teaching period."

The skills required for academic achievement are generally acquired over a period of time, as identified with my emic view as a Malaysian and UK academic stance. As nurses' previous learning focused on assimilation of information and providing correct answers, they struggled with the new academic literacy skills. These nurses also had to fast track their learning due to the short-time frame allocated to teaching on the module. Further, support to complete their assessments was only by email exchanges. 
From personal analysis, the shortness of the teaching delivery make these programmes vulnerable to criticisms about academic standards. The UK academic view highlights that the quality of the programme is not assured through following models of knowledge that worked in the UK. Further, the academic standards achievable on such short courses are unlikely to meet those required of degree programmes in the host country. This has implications against both eastern and western academic standards.

\section{Shock and coping strategies and acclimatisation.}

Participants described how initial excitement of being successful in being accepted and offered a place on the TNHE programme quickly on the first few days gave way to a sense of shock and disorientation that exacerbated their feelings of anxiety, frustration, uncertainty and self-doubts. The experience proved more demanding, compared to their previous class contact hours and pace of teaching delivery, than they had expected. Bartram (2008) taxonomy identified three key areas i.e. social, academic and practical that international students require assistance. In this instance, nurses struggled as they were accustomed to a pedagogical approach that was different, thus, they experienced 'learning culture shock'. Teras (2013) argues in taking the cultural aspect into consideration, it does not mean trying to make the learning environment familiar to these students, instead it is to develop an environment that promotes cultural sensitivity, appreciation for diversity and dialogue for all learners.

Their experience of each module was summed up by all the nurses as similar to using a "remote control" (Int: 010) - "switch on, switch off" (Int: 011). Interviewee 016 clarified this succinct portrayal of the TNHE teaching as "talk, talk, talk, fast, fast, fast then bye-bye". The "compressed" (Int: 012) or "toooooooooooo short" (Int: 017) teaching time-frame resulted in "everything was like a blur" (Int: 009).

Kalervo Oberg in 1960 introduced the concept of culture shock and the importance for the 'honeymoon' period as it provides time for a gradual adjustment and acclimatisation. These nurses were deprived of this time-frame to adjust to the new thinking, writing and academic practices like those required for TNHE programmes. After their initial flight response to quickly recognise the need to use coping strategies to fight and overcome their shock and confront the challenges. The tendency for international students to take flight or fight when confronted with obstacles was acknowledged by Anderson (1994).

On reflection it clarifies that they used their effortful and respectful learning to deal with adjustment demands for the instrumental end. My UK academic view highlights the idealised Western education that these nurses were keen to experience and the western degree qualification that was deemed superior, pressurised them to adjust.

\section{Main outcomes}

The findings and lessons learnt identify key aspects to be considered by schools of nursing that intend to, or already provide collaborative TNHE programmes. The data is also relevant to all those engaged in international collaboration and higher education, including other professions, and all TNHE programmes delivered in South East Asian countries, where strong cultural factors continue to affect society.

\section{Discussion}

It is recognised that it can be difficult to pitch the language, teaching and learning, theoretical knowledge, assessment, guidance and support to a level suitable for all students 
(Hénard \& Roseveare, 2012; Joy \& Kolb, 2009). In this study, nurses identified that within the modular framework of TNHE teaching, learning and assessment: a) classroom experiences were short, overwhelming, western centric and assessment focused; b) TNHE academics appeared unaware of nurses' education systems and reasons for their classroom behaviours; c) academic standards varied but too little explanation on how to meet them was given; d) writing assignments was a new experience for most nurses; e) explicit assessment criteria was desired; f) guidance and face-to-face support was required for completing assessments and g) email contact for assessment support needs to be enhanced. Based on the data, it appears that TNHE programmes were being delivered within unrealistic time-frames and teaching was not pitched to the students' level of education. In addition, too much subject knowledge for each module was taught within an unrealistically short time-frame which meant nurses had to fast track their learning. Limited guidance and face-to-face and online support were also provided to complete the assessments. Mainly, it took place against what they understood to be good learning, teaching, assessment, guidance and support practices.

Previously, Ziguras (2008) strongly recommended academics to be familiar with their student's backgrounds, assumptions and expectations. In fact, Ziguras stressed that academics have a professional responsibility to learn and use this knowledge in teaching. Hunter, Leask, and Rumbley (2014) identify the challenges HEIs face within the short time frames and limited resources for TNHE provision but agree strategies need to be developed to overcome them. Despite these challenges and difficulties nurses made the necessary adjustments to meet the assessment criteria and achieve their western degrees successfully.

\section{Conclusions}

This paper has presented participants' perspectives of their TNHE teaching and learning experiences with an emic and etic interpretation. It identified the challenges nurses experienced in the new academic context and the necessary adjustments they made to meet the assessment criteria and successfully achieve their western degrees. The Malaysian nurses views of their intercultural and TNHE classroom experiences highlights the importance for 'flying faculty'to internationalise the theoretical knowledge by integrating Malaysian values within the Western ways of knowing to enhance their learning experiences.

\section{References}

Abdullah, A., 2010. Culture Influences on Learning and Thinking. October 10th Presentation at Seri Pacific Hotel. Kuala Lumpur. 
Abdullah, F., 2009. Guidelines for continuous professional development (CPD) programme for nurses/midwives: Message from the Director of Nursing, Ministry of health, Malaysia. Malaysian Journal of Nursing. 1(1), 3.

Abdullah, A., Koh, S.L., 2009. Culture Matters in Malaysia. Pearson Prentice Hall. Kuala Lumpur.

Ahmad, S.Z., \& Buchanan, F.R., 2016. Choices of destination for transnational higher education:"pull" factors in an Asia Pacific market. Educational Studies 42 (2), 163-180.

Amir, S., 2009. The influence of national culture on communication practices: A case study on Malaysian Organisation. Masters dissertation. Queensland University of Technology.

Anderson, L. E., 1994. A New Look at an Old Construct: Cross-Cultural Adaptation. International Journal of Intercultural Relations. 18, 293-328.

Arunasalam, N. D., 2013. A defining moment: Malaysian nurses' perspectives of transnational higher education (Doctoral dissertation, University of Hertfordshire). Retrieved from http://hdl.handle.net/2299/11561

Arunasalam, N.D., 2017. Transnational Nursing Education. Transnational Press London. London.

Bartram, B., 2008. Supporting international student in higher education: constructions, culture and clashes, Teaching in Higher Education. 13(6), 657- 668.

Benner, P. 1994. Interpretive phenomenology: Embodiment, caring, and ethics in health and illness. Sage. California, Thousand Oaks.

Biggs, J., 2014. Constructive alignment in university teaching. HERDSA Review of Higher Education. 1, 5-22.

British Education Research Association., 2011. Ethical Guidelines for Educational Research. http://tinyurl.com/pb6h5nn (accessed 10 October 2017)

Cohen L, Manion L, Morrison, K., 2011. Research Methods in Education. Routledge. London.

Dempsey L, Dowling M, Larkin P, Murphy K., 2016. Sensitive Interviewing in Qualitative Research. Research Nursing Health. 39(6), 480-490.

Dowling, M., 2007. International credentialing, certification, and recognition in the United States. New Library World. 108 (1/2). 79-82

Geertz, C., 1973. The interpretation of cultures: Selected essays. Basic Books. New York.

Gill, S.K., 2009. Language Education Policy in Multi-Ethnic Malaysia. In The Routledge International Companion to Multicultural Education. Banks, J.A. 397-409. New York. Routledge/Taylor and Francis. 
Gow, L., \& Kember, D., 1990. Does Higher Education Promote Independent Learning? Higher Education. 19, 307-322.

Hassan, H. 2010. Development of Nursing Education in Malaysia towards the year 2020. Department of Higher Education, Ministry of Health Malaysia. Shah Alam. University Publication Centre (UPENA).

Hassan, A. and Jamaludin, N.S., (2010). Approaches and values in two gigantic educational philosophies: East and West. Selangor, Malaysia. University Putra Malaysia.

Hénard, F., Roseveare, D., 2012. Fostering Quality Teaching in Higher Education: Policies and Practices. Organisation for Economic Co-operation and Development (OECD).

G Hofstede, G \& Hofstede, GF, 2005. Cultures and Organizations: Software of the Mind, second edition. London. McGraw-Hill.

Ibrahim, A.R., Nik Yusoff, N.M.R. and Kamarudin, M.Y., 2016. Mobile Learning Quality of Education and Increase in Student Discipline. Creative Education. 7(4). April 11.

Hunter, F., Leask, B., \& Rumbley, L. (2014). Editorial. Journal of Studies in International Education. 18, 199-201.

Joy, S., \& Kolb, D. A., 2009. Are there cultural differences in learning style? International Journal of Intercultural Relations. 33(1), 69-85.

Kirby, P., Lanyon, C., Cronin, K., Sinclair, R., 2003. Building a Culture of Participation National Children's Bureau. London.

Knight, J., 2004. Internationalisation remodeled: Definition, approaches, and rationales. Journal of Studies in International Education. 8, 5-31.

Knight, J., 2011. Education hubs: a fad, a brand, an innovation? Journal of Studies in International Education. 15(3), 221-40.

Knight, J., 2015. Five myths about internationalization. International Higher Education. 62, 14-15.

Knight, J., 2015. New rationales driving internationalization. International Higher Education. 34, 1-3.

Leshchenko, M., Avshenyuk, N., 2015. Philosophical and Pedagogical Principles of Transnational Higher Education Development. Comparative Professional Pedagogy. 5(3), 4652.

Li, Y.W., 2016. Transforming Conventional Teaching Classroom to Learner-Centred Teaching Classroom Using Multimedia-Mediated Learning Module. International Journal of Information and Education Technology, 6(2). February.

Leask, B. and Carroll, J., 2011. Moving beyond 'wishing and hoping': internationalisation and student experiences of inclusion and engagement. Higher Education Research and Development, 30 (5). 647-659. 
Malaysian Nursing Board., 2008. Guidelines for continuous professional development programme for nurses/midwives. Nursing Division, Ministry of Health Malaysia. Putrajaya, Malaysia.

Merriam, S. B., 2009. Qualitative research: A guide to design and implementation. John Wiley \& Sons. San Francisco.

Oberg, K., 1960. Culture Shock: Adjustment to New Culture Environments. Practical Anthropology. 7, 177-182.

O’Mahony, J., 2014. Enhancing student learning and teacher development in transnational education. Higher Education Academy. York, UK.

Pike, K., 1967. Language in relation to a unified theory of the structure of human behaviour (2nd ed.). Mouton. The Hague, The Netherlands.

Polit, D., Beck, C., 2010. Essentials of nursing research-Appraising evidence for nursing practice. Wolters Kluwer Health. Philadelphia.

Sidhu, R.K., Christie, P., 2015. Transnational higher education as a hybrid global/local space: A case study of a Malaysian-Australian joint venture. Journal of Sociology. 51(2), 299-316.

Teras, H.M., 2013. Dealing with "learning culture shock" in multicultural authentic elearning. University Of Wollongong, Faculty of Social Sciences. Australia.

Van Manen, M., 2014. Phenomenology of practice: Meaning-giving methods in phenomenological research and writing. Left Coast Press. California.

Willig, 2013. Introducing Qualitative Research In Psychology. McGraw-Hill Education. Berkshire, UK.

Ziguras, C., 2008. The cultural politics of transnational education: Ideological and pedagogical issues for teaching staff. In L. Dunn \& M. Wallace (Eds.), Teaching in transnational higher education: Enhancing learning for offshore international students. (4454). Routledge. Oxon, UK. 